\title{
Clinical relevance of intra-abdominal adhesions in cesarean delivery
}

\author{
Togas Tulandi • Baydaa Al-Sannan • Ghadeer Akbar • \\ Louise Miner • Cleve Ziegler • Vanja Sikirica
}

Received: 16 January 2011 / Accepted: 20 January 2011 /Published online: 12 February 2011

(C) Springer-Verlag 2011

\begin{abstract}
The objective of this study was to evaluate the prevalence and extent of intra-abdominal adhesions at cesarean deliveries (CS) and their clinical relevance. We studied 490 cases of primary CS, 430 first repeat, and 106 cases of second or third repeat CS. Using a standard scoring system, the prevalence, extent, and consistency of adhesions were evaluated prospectively. We also examined the incisiondelivery interval and the total operating time. At repeat CS, adhesions were found mainly between the uterus and the bladder or the abdominal wall. Dense adhesions to the bladder and to the abdominal wall were significantly more after $\geq 2$ CSs $(46.3 \%$ and $48.2 \%)$ than after one CS $(29.8 \%$ and $25.6 \%)$. The adhesions on these areas were also more severe after $\geq 2$ CSs than after one CS. There was a significant correlation between the adhesion score and the interval between the incision and delivery $(r=0.23, P<0.0001)$ and the operating time $(r=0.26, P<0.0001)$. CS leads to adhesion formation mainly between the uterus and the bladder and between the uterus and the anterior abdominal wall.
\end{abstract}

Keywords Cesarean · Repeat cesarean · Adhesion · Delivery time - Operating time

T. Tulandi $(\bowtie) \cdot$ B. Al-Sannan $\cdot$ G. Akbar $\cdot$ L. Miner $\cdot$ C. Ziegler From the Department of Obstetrics and Gynecology,

McGill University,

687 Pine Ave. West,

Montreal, H3A 1A1 QC, Canada

e-mail: togas.tulandi@mcgill.ca

V. Sikirica

Ethicon, Inc,

Somerville, NJ, USA

\section{Objective}

In 1965, when it was first measured, the US national cesarean delivery (CS) rate was $4.5 \%$ [1]. In 2007, national vital statistics data estimates indicated that $31.8 \%$ of all deliveries were via the CS route in the US. It marks the 11th year in a row that the rates increased and a new alltime high [2]. This has made CS the most common operation performed on US women with 1.37 million cesareans in 2007 [2].

Similar to other abdominal operations, CS is associated with intra-abdominal adhesions leading to longer operating time with subsequent cesareans. The results of the few studies on adhesion development are congruent with each other in the direction of effect, indicating that adhesion develop more and with greater density with each repeat cesarean section. For example, Morales et al. found that 46-83\% of women develop adhesions after repeat CS (second through fourth CS), and the extent and density of the adhesions increased with each repeat CS [3]. In another study, Tulandi et al. reported increased adhesion development and longer time to delivery in subsequent cesarean [4].

The aim of our study was to evaluate the prevalence and extent of intra-abdominal adhesions after CS and their clinical implications.

\section{Materials and methods}

The study was performed in the Department of Obstetrics and Gynecology at the Sir Mortimer B. Davis, Jewish General Hospital, a McGill University teaching hospital in Montreal from 2008 to 2009. We studied 1,026 women who underwent CS. Using a standard adhesion scoring system, the prevalence, extent, and consistency of adhesions at the time of CS 
were graded prospectively. We also examined the incisiondelivery interval (delivery time), the total operating time, as well as the Apgar score and the fetal cord $\mathrm{pH}$ of the baby, and the postoperative complication prospectively.

Demography of the patients and other medical information were retrospectively retrieved from the hospital medical charts and independently crosschecked twice by two of the study investigators (BAS and GA). Patients who had had previous uterine surgery by abdominal approach such as myomectomy, cesarean with classical or T incision, history of pelvic infection, presence of stage III or IV endometriosis, and those with incomplete adhesion score were excluded.

The primary outcome measures were the prevalence, extent and consistency of adhesions, the incision-delivery interval, and the operative time at the primary cesarean or repeat CS. The secondary outcome measures were Apgar score and fetal cord $\mathrm{pH}$ of the newborn. The site and nature of adhesions were graded using an adhesion scoring system. We graded adhesions at four adhesion sites, and assigned a score of 0 for no adhesions, 1, 2, or 3 for filmy adhesions and 2, 4 or 8 for dense adhesions. The extent of adhesions was marked as enclosing $\leq 1 / 3,1 / 3$ to $2 / 3$, or $>2 / 3$ of the previous cesarean incision, respectively.

\section{Statistical analysis}

Normality of data distribution was tested using the Shapiro-Wilk's test. For continuous variables, inferential testing was conducted using the Student $t$ test for normally distributed data. For non-normally distributed data, the Mann-Whitney test was used. Proportions were compared using Chi-Square or Fisher's exact test when appropriate. The differences were considered significant if $P$ was less than 0.05 .

Table 1 Profile of 1,026

women who underwent primary cesarean delivery (CS), one repeat and over two-repeat cesareans

\begin{tabular}{llll}
\hline & $\begin{array}{l}\text { Primary } \\
(n=490)\end{array}$ & $\begin{array}{l}\text { Repeat 1 CS } \\
(n=430)\end{array}$ & $\begin{array}{l}\text { Repeat } \geq 2 \text { CS } \\
(n=106)\end{array}$ \\
\hline Age & $32.5 \pm 0.2$ & $34.6 \pm 0.2$ & $34.8 \pm 0.5$ \\
Gravidity & $1.9 \pm 0.9$ & $2.9 \pm 0.05$ & $3.8 \pm 0.2$ \\
Parity & $0.4 \pm 0.04$ & $1.5 \pm 0.03$ & $2.0 \pm 0.08$ \\
Ethnicity & & & \\
Caucasian & $273(55.7 \%)$ & $218(50.7 \%)$ & $54(50.9 \%)$ \\
Asian & $53(10.8 \%)$ & $77(17.9 \%)$ & $8(7.5 \%)$ \\
African descent & $66(13.5 \%)$ & $56(13 \%)$ & $25(23.6 \%)$ \\
Hispanic & $71(14.5 \%)$ & $62(14.4 \%)$ & $13(12.3 \%)$ \\
Others & $27(5.5 \%)$ & $17(4 \%)$ & $6(5.7 \%)$ \\
\hline
\end{tabular}

Table 2 Prevalence, site and extent of adhesions at repeat cesarean delivery (CS)

Repeat 1 CS (430) Repeat $\geq 2$ CS (106) $P$ value

Filmy adhesion, uterus to bladder

$\begin{array}{lcll}1 / 3 \text { adhesion } & 155(36.0 \%) & 30(28.3 \%) & \text { NS } \\ 1 / 3-2 / 3 \text { adhesion } & 52(12.1 \%) & 13(12.3 \%) & \text { NS } \\ >2 / 3 \text { adhesion } & 32(7.4 \%) & 13(12.3 \%) & \text { NS } \\ \text { Total } & 239(55.5 \%) & 56(52.9 \%) & \text { NS }\end{array}$

Dense adhesion, uterus to bladder

\begin{tabular}{|c|c|c|c|}
\hline $1 / 3$ adhesion & $70(16.3 \%)$ & $20(18.9 \%)$ & NS \\
\hline $1 / 3-2 / 3$ adhesion & $39(9.1 \%)$ & $14(13.2 \%)$ & NS \\
\hline$>2 / 3$ adhesion & $19(4.4 \%)$ & $15(14.2 \%)$ & 0.0005 \\
\hline Total & $128(29.8 \%)$ & $49(46.3 \%)$ & 0.001 \\
\hline \multicolumn{4}{|c|}{ Filmy adhesion, uterus to abdomen } \\
\hline $1 / 3$ adhesion & $102(23.7 \%)$ & $19(17.9 \%)$ & NS \\
\hline $1 / 3-2 / 3$ adhesion & $35(8.1 \%)$ & $11(10.4 \%)$ & NS \\
\hline$>2 / 3$ adhesion & $14(3.3 \%)$ & $6(5.7 \%)$ & NS \\
\hline Total & $151(35.1 \%)$ & $36(34 \%)$ & NS \\
\hline \multicolumn{4}{|c|}{ Dense adhesion, uterus to abdomen } \\
\hline $1 / 3$ adhesion & $58(13.5 \%)$ & $22(20.8 \%)$ & NS \\
\hline $1 / 3-2 / 3$ adhesion & $38(8.8 \%)$ & $16(15.1 \%)$ & NS \\
\hline$>2 / 3$ adhesion & $14(3.3 \%)$ & $13(12.3 \%)$ & 0.0004 \\
\hline Total & $110(25.6 \%)$ & $51(48.2 \%)$ & 0.0001 \\
\hline
\end{tabular}

Filmy adhesion, uterus to intestine

$\begin{array}{lcrl}1 / 3 \text { adhesion } & 44(10.2 \%) & 10(9.4 \%) & \text { NS } \\ 1 / 3-2 / 3 \text { adhesion } & 10(2.3 \%) & 4(3.8 \%) & \text { NS } \\ >2 / 3 \text { adhesion } & 1(0.2 \%) & 3(2.8 \%) & <0.05 \\ \text { Total } & 55(12.7 \%) & 17(16 \%) & \text { NS }\end{array}$

Dense adhesion, uterus to intestine

$\begin{array}{lccl}1 / 3 \text { adhesion } & 11(2.6 \%) & 5(4.7 \%) & \text { NS } \\ 1 / 3-2 / 3 \text { adhesion } & 6(1.4 \%) & 1(0.9 \%) & \text { NS } \\ >2 / 3 \text { adhesion } & 3(0.7 \%) & 3(2.8 \%) & \text { NS } \\ \text { Total } & 20(4.7 \%) & 9(8.5 \%) & \text { NS } \\ \text { Filmy adhesion, uterus to omentum } & & \\ 1 / 3 \text { adhesion } & 63(14.7 \%) & 20(18.9 \%) & \text { NS } \\ 1 / 3-2 / 3 \text { adhesion } & 19(4.4 \%) & 10(9.4 \%) & \text { NS } \\ >2 / 3 \text { adhesion } & 2(0.5 \%) & 5(4.7 \%) & 0.002 \\ \text { Total } & 84(19.6 \%) & 35(33 \%) & 0.004\end{array}$

Dense adhesion, uterus to omentum

\begin{tabular}{lccl}
$1 / 3$ adhesion & $35(8.1 \%)$ & $10(9.4 \%)$ & NS \\
$1 / 3-2 / 3$ adhesion & $17(4 \%)$ & $5(4.7 \%)$ & NS \\
$>2 / 3$ adhesion & $2(0.5 \%)$ & $3(2.8 \%)$ & NS \\
Total & $54(12.6 \%)$ & $18(16.9 \%)$ & NS \\
\hline
\end{tabular}

\section{Results}

Of 1,026 women, 490 had had primary CS, 430 women had one repeat CS and 106 had two or three-repeat CSs. The number of women who had undergone three-repeat CS was 


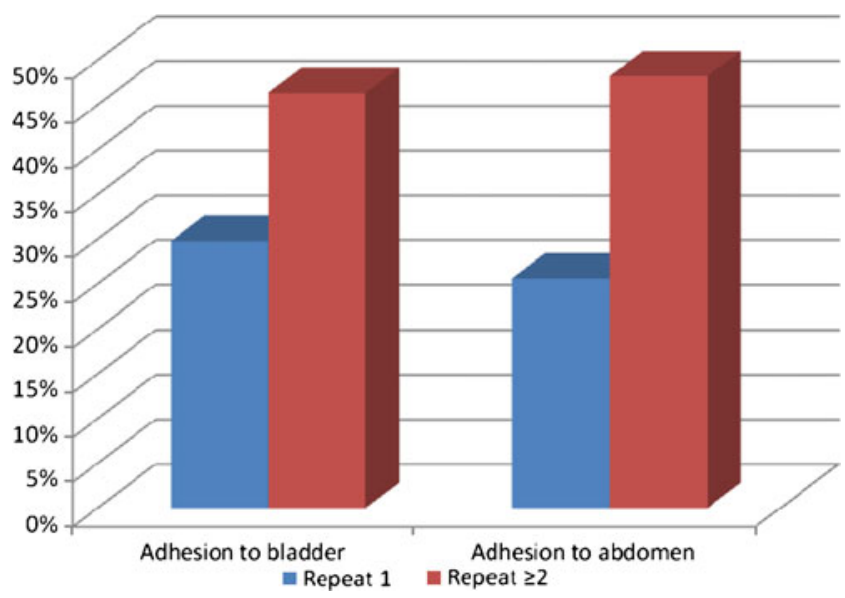

Fig. 1 Dense adhesions between the uterus and the bladder and between the uterus and the abdominal wall at repeat cesarean delivery

only 12. Accordingly, we combined cases that had undergone two- and three-repeat cesareans. The mean age of the patients who underwent primary CS, one repeat CS and $\geq 2$ repeat CSs were $32.5 \pm 0.2$ years, $34.6 \pm 0.2$ years, and $34.8 \pm 0.5$ years, respectively. Other demographic data were comparable (Table 1). None of the patients had previous adhesion barrier placement.

No adhesions were found in women who underwent primary cesarean. At repeat CS, adhesions were found mainly between the uterus and the bladder, and between the uterus and the anterior abdominal wall (Table 2). Dense adhesions between the uterus and the bladder and between the uterus and the abdominal wall were significantly higher after $\geq 2$ CSs $(46.3 \%$ and $48.2 \%)$ than after one CS $(29.8 \%$ and 25.6\%; Table 2, Fig. 1). The adhesions on these areas were also more severe after $\geq 2$ CSs than after one CS (Table 3). The estimated blood loss was $672.1 \pm 8.9 \mathrm{ml}$ at primary CS, $628.7 \pm 7.8 \mathrm{ml}$ at $2 \mathrm{nd} \mathrm{CS}$, and $659.9 \pm 21.4 \mathrm{ml}$ at third CS, respectively. Figure 2 shows dense adhesions between the uterus and anterior abdominal wall in a woman who had had a CS.

Compared to those of primary CS, the incisiondelivery interval (Fig. 3) and the operating time were also higher at repeat emergency and elective CSs (Table 4). There were small, but significant correlations found

Table 3 Adhesion score at repeat cesarean delivery (CS)

\begin{tabular}{lccl}
\hline Site of adhesions & Repeat 1 CS & Repeat $\geq 2$ CS & $P$ value \\
\hline Uterus-bladder & $4.2 \pm 0.2$ & $6.2 \pm 0.6$ & 0.01 \\
Uterus-abdominal wall & $4.6 \pm 0.3$ & $7.0 \pm 0.6$ & 0.001 \\
Uterus-intestine & $3.5 \pm 0.5$ & $4.9 \pm 1.4$ & NS \\
Uterus-omentum & $3.8 \pm 0.3$ & $4.3 \pm 0.8$ & NS \\
\hline
\end{tabular}

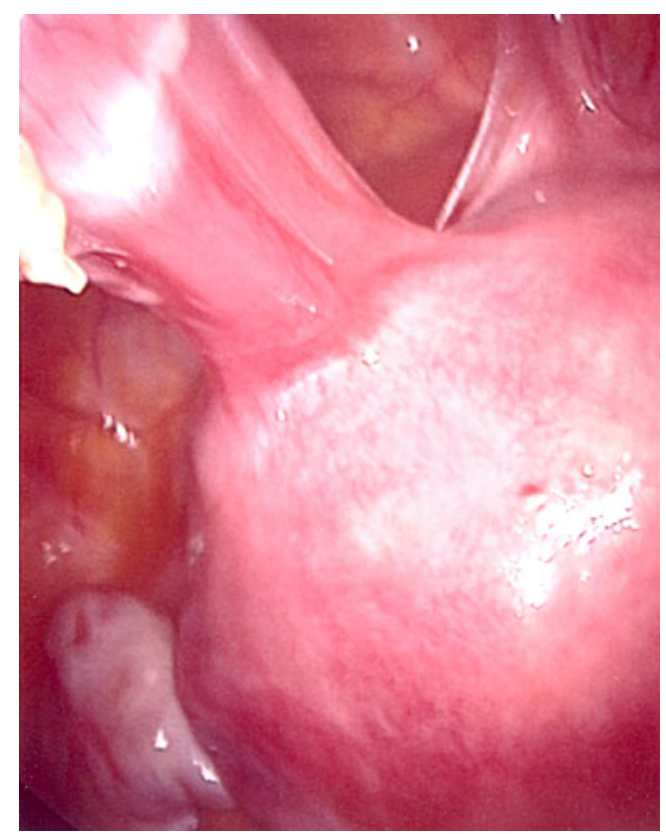

Fig. 2 Dense adhesions between the uterus and the anterior abdominal wall in a woman who had had a cesarean delivery

between the adhesion score and the interval between the incision and delivery $(r=0.23, P<0.0001$, Fig. 4$)$ and the operating time $(r=0.26, P<0.0001)$ in all cases. There was no significant difference in the Apgar score and in the fetal cord $\mathrm{pH}$ among those who had had primary CS, repeat one or repeat $\geq 2$ CSs (all over 8.8 and 7.3, respectively). Furthermore, there was no correlation between the total adhesion score and fetal cord $\mathrm{pH}$; among all women who underwent repeat CS as well as in those who underwent repeat emergency CS.

We encountered two intraoperative complications. One woman with placenta accreta underwent cesarean hysterec-

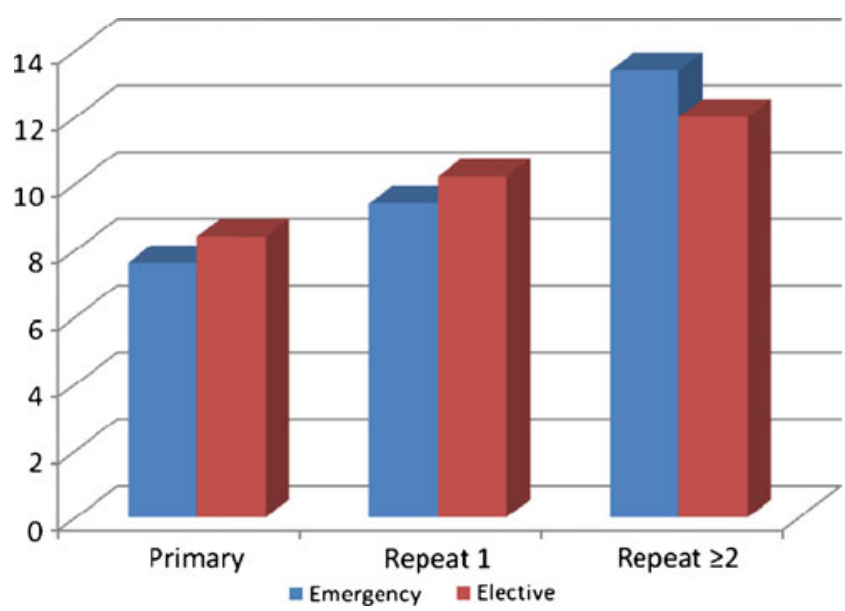

Fig. 3 Incision-delivery interval at repeat cesarean delivery for elective and emergency cases 
Table 4 Incision-delivery interval and operating time at repeat emergency and elective cesarean deliveries

\begin{tabular}{|c|c|c|c|c|c|}
\hline & Primary $(n=490)$ & Repeat 1 CS $(n=430)$ & $P$ value & Repeat $\geq 2$ CS $(n=106)$ & $P$ value \\
\hline Emergency cesarean & $345(70.4 \%)$ & $100(23.3 \%)$ & & $18(17 \%)$ & \\
\hline Incision-delivery interval (min) & $7.6 \pm 0.3$ & $9.4 \pm 0.5$ & $<0.001$ & $13.4 \pm 1.8$ & $<0.001$ \\
\hline Operating time (min) & $39.4 \pm 0.7$ & $40.7 \pm 1.4$ & NS & $46.2 \pm 2.9$ & $<0.05$ \\
\hline Elective cesarean & $145(29.6 \%)$ & $330(76.7 \%)$ & & $88(83 \%)$ & \\
\hline Incision-delivery interval (min) & $8.4 \pm 0.3$ & $10.2 \pm 0.3$ & 0.002 & $12.01 \pm 0.6$ & 0.0001 \\
\hline Operating time $(\min )$ & $39.4 \pm 0.9$ & $39.55 \pm 0.8$ & NS & $45.0 \pm 1.6$ & 0.005 \\
\hline
\end{tabular}

tomy and another with severe adhesions suffered bowel injury at the third CS requiring segmental bowel resection.

\section{Comment}

The results of our study showed that at repeat CS, adhesions were found mainly between the uterus and the bladder, and between the uterus and the anterior abdominal wall. This is in agreement with previous reports [3, 4]. Adhesions on these areas were also more severe after $\geq 2$ CSs than after one cesarean. As previously suggested [3], it is very likely that the presence of these adhesions increases the incision-delivery interval delaying the birth of the newborn. In theory, it might be deleterious to the health of the baby. Yet in our series, we did not find any correlation between the total adhesion score and fetal cord $\mathrm{pH}$. A much larger study is needed to clarify this matter. Besides increased incision-delivery interval, it also took longer to complete surgery at repeat CS. Again, this is related to increased adhesion score.

Adhesions to the bladder might be associated with bladder injury at subsequent CS. The estimated incidence of bladder injury is about three to four per 1,000 repeat cesareans. Silver et al. found that the incidence of bladder laceration increased from $0.13 \%$ at a primary CS to $1.94 \%$ at the fifth CS [5]. No bladder injury was found in our series. Yet, we encountered adhesion-related bowel injury necessitating bowel resection. Bowel obstruction in the postpartum period due to post-cesarean adhesion has also been reported [6]. However, it usually occurs long after the initial surgery. The prevalence of bowel obstruction after CS has been estimated to be one per 1,000 cesareans [7].

Adhesions lead to a difficulty to perform subsequent CS as well as other abdominal operations. For example, Wang et al. reported higher rates of major complications in patients undergoing laparoscopic hysterectomy with previous $\mathrm{CS}$; the higher the number of previous CS, the higher the rate
Fig. 4 Correlation between the adhesion score and the interval between the incision and delivery $(r=0.23, P<0.0001)$

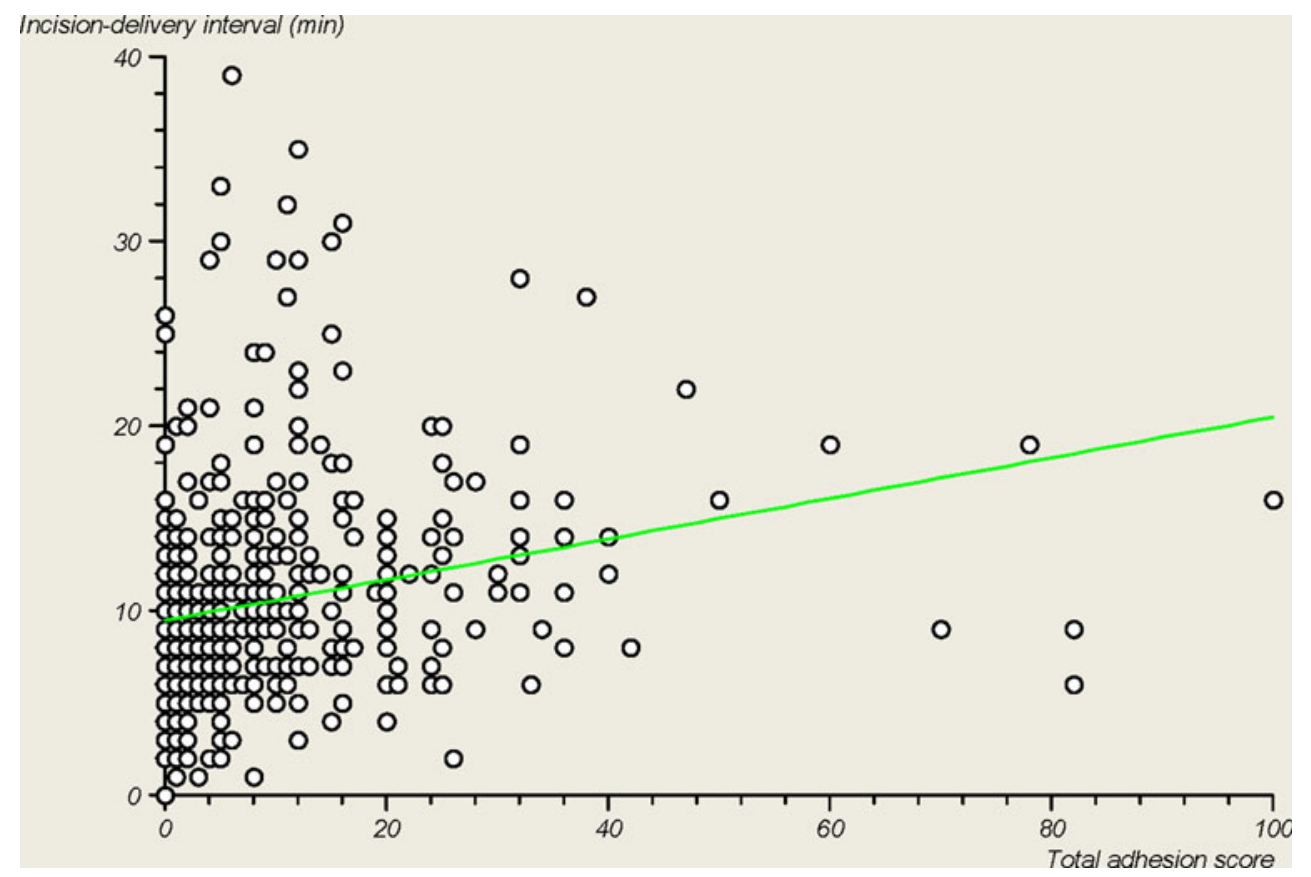


of complications [8]. The most significant increase is seen in patients with more than two previous CS deliveries. Clearly, as previously reported morbidity increases with increasing number of deliveries [3-5, 9-11].

In attempts to decrease adhesion formation, several authors have evaluated different techniques of performing cesareans. In a chart review, a technique described at Misgav Ladach Hospital in Israel was associated with less intraabdominal adhesions than the standard technique [12]. This non-conventional technique involves a transverse incision higher than the Pfannenstiel incision, and blunt separation of the rectus muscles, opening of the peritoneum as well as the uterine incision. The uterus is then closed with a one-layer continuous locking stitch. The visceral and parietal peritoneal layers are left unsutured. Whether, this technique is indeed associated with less adhesion formation remains unclear. In fact, two reports might contradict their assumption $[13,14]$. Blumenfeld et al. reported that single layer closure of the hysterotomy incision was associated with more bladder adhesions at the time of repeat CS than doublelayer closure [13]. There is also evidence that that nonclosure of the peritoneum after cesarean section is associated with more adhesion formation compared to closure [14].

Our study has some limitations. Instead of relying on timed second-look laparoscopy, we evaluated adhesions at repeat cesarean delivery. A second-look procedure especially in postpartum women is inconvenient for new mothers and their baby, but would likely yield more accurate results. Our study was only from one center. While we have large volume in our practice, these results may not be fully applicable to other institutions with different practice patterns or techniques.

We conclude that cesarean delivery leads to adhesion formation mainly between the uterus and the bladder and between the uterus and the anterior abdominal wall. Repeat cesarean is associated with longer delivery and operating times due to the presence of adhesions.

Declaration of interest The authors report no conflicts of interest. The authors alone are responsible for the content and writing of the paper.

\section{References}

1. Taffel SM, Placek PJ, Liss T (1987) Trends in the United States cesarean section rate and reasons for the 1980-85 rise. Am J Public Health 77:955-959

2. Hamilton BE, Martin JA, Ventura SJ (2007) Births: preliminary data for 2006. Natl Vital Sat Rep 56:1-18

3. Morales KJ, Gordon MC, Bates GW Jr (2007) Postcesarean delivery adhesions associated with delayed delivery of infant. Am J Obstet Gynecol 196:461.e1-461.e6

4. Tulandi T, Agdi M, Zarei A, Miner L, Sikirica V (2009) Adhesion formation and morbidity after repeat cesarean delivery. Am J Obstet Gynecol 201:56.e.1-56.e.6

5. Silver RM, Landon MB, Rouse DJ, Leveno KJ, Spong CY, Thom EA, Moawad AH et al (2006) Maternal morbidity associated with multiple repeat cesarean deliveries. Obstet Gynecol 107:1226-1232

6. Zahumensky J, Zmrhalova B, Sottner O, Maxova K, Brtnicka H, Horak J, Binder T, Halaska M (2010) Adhesive bowel strangulation after cesarean section, the rare puerperal complication. Prague Med Rep 111:65-68

7. Al-Sunaidi M, Tulandi T (2006) Adhesion-related bowel obstruction after hysterectomy for benign conditions. Obstet Gynecol 108:1162-1166

8. Wang L, Merkur H, Hardas G, Soo S, Lujic S (2010) Laparoscopic hysterectomy in the presence of previous cesarean section: a review of one hundred forty-one cases in the Sydney West advanced pelvic surgery unit. J Min Inv Gynecol 17:186-191

9. Phipps MG, Watabe B, Clemons JL, Weitzen S, Myers DL (2005) Risk factors for bladder injury during cesarean delivery. Obstet Gynecol 105:156-160

10. Cahill AG, Stout MJ, Stamilio DM, Odibo AO, Peipert JF, Macones GA (2008) Risk factors for bladder injury in patients with a prior hysterotomy. Obstet Gynecol 112:116-120

11. Nisenblat V, Barak S, Griness OB, Degani S, Ohel G, Gonen R (2006) Maternal complications associated with multiple cesarean deliveries. Obstet Gynecol 108:21-26

12. Fatusic Z, Hudic I (2009) Incidence of post-operative adhesions following Misgav Ladach cesarean section - a comparative study. J Matern-Fetal Neonatal Med 22:157-160

13. Blumenfeld YJ, Caughey AB, El-Sayed YY, Daniels K, Lyell DJ (2010) Single- versus double-layer hysterotomy closure at primary cesarean delivery and bladder adhesions. BJOG: Int J Obstet Gynaecol 117:690-694

14. Cheong YC, Premkumar G, Metwally M, Peacock JL, Li TC (2009) To close or not to close? A systematic review and a metaanalysis of peritoneal non-closure and adhesion formation after cesarean section. Eur J Obstet Gynecol Reprod Biol 147:3-8 